\title{
Enhanced Activity of Immunosuppressive Oligodeoxynucleotides by Incorporating Them into Hexapod-Like Nanostructured DNA
}

\author{
Yuki Araie, ${ }^{a}$ Yosuke Takahashi, ${ }^{a}$ Yuki Takahashi, ${ }^{a}$ Yoshinobu Takakura, ${ }^{a}$ and \\ Makiya Nishikawa*,a,b \\ ${ }^{a}$ Department of Biopharmaceutics and Drug Metabolism, Graduate School of Pharmaceutical Sciences, Kyoto \\ University; 46-29 Yoshida-Shimo-Adachi, Sakyo-ku, Kyoto 606-8501, Japan: and ${ }^{b}$ Laboratory of Biopharmaceutics, \\ Faculty of Pharmaceutical Sciences, Tokyo University of Science; 2641 Yamazaki, Noda, Chiba 278-8510, Japan. \\ Received October 25, 2017; accepted January 8, 2018
}

\begin{abstract}
A151 and other immunosuppressive oligodeoxynucleotides that act as Toll-like receptor (TLR) 9 antagonists are candidate agents for the treatment of autoimmune and inflammatory diseases in which TLR9 activation leads to harmful immune responses. Their efficient delivery to TLR9-positive target cells will increase their potency, but few attempts have been made to enhance their delivery. We previously reported that hexapod-like nanostructured DNA (hexapodna) enhanced the activity of immunostimulatory cytosinephosphate-guanine (CpG) DNA by efficiently delivering it to immune cells. In this study, to enhance the immunosuppressive activity of A151, we designed a hexapodna containing six copies of the complementary sequence to A151. Structural analyses showed that A151-loaded hexapodna (supHexapodna) was obtained as designed. CpG 1668, which is a typical synthetic CpG DNA, induced tumour necrosis factor- $\alpha$ release from mouse macrophage-like RAW264.7 cells, and supHexapodna inhibited this more efficiently than A151. A flow cytometric analysis showed that the uptake of Alexa Fluor 488-labelled A151 by RAW264.7 cells significantly increased when it was incorporated into supHexapodna, whereas the uptake of Alexa Fluor 488-labelled CpG 1668 was hardly affected by A151 or supHexapodna. These results suggest that the hexapodna-mediated delivery of A151 can increase the potency of its TLR9-inhibitory activity towards immune cells.
\end{abstract}

Key words drug delivery; immunosuppressive oligodeoxynucleotide; nanotechnology; drug targeting; Tolllike receptor 9; immune response

The severe exacerbation of immune responses causes autoimmune and inflammatory diseases. The innate immune system is activated by Toll-like receptor (TLR) signalling complexes. ${ }^{1)}$ For example, bacterially-derived unmethylated cytosine-phosphate-guanine (CpG) DNA and lipopolysaccharide bind to TLR9 and TLR4, respectively, leading to the induction of immune responses following cytokine and chemokine release.

Immunosuppressive oligodeoxynucleotides (ODNs) are expected to reduce exacerbated immune responses and are candidate agents for the treatment of autoimmune and inflammatory diseases such as inflammatory arthritis, cancer, and so on. ${ }^{2,3)}$ Some immunosuppressive ODNs, such as guaninerich ODNs, competitively bind to TLR9 with CpG DNA and down-regulate CpG DNA-induced immune activation., ${ }^{45)}$ A151 is a partially TLR9-independent immunosuppressive ODN with a phosphorothioate backbone. It inhibits the binding of CpG DNA to TLR9 and also inhibits Janus kinase (JAK)signal transducer and activator of transcription (STAT) signalling by directly binding to STAT proteins and hindering their phosphorylation. ${ }^{6,7)}$ The immunosuppressive activity of A151 relies on its anti-parallel G-quadruplex conformation, which arises from its repetitive TTAGGG sequence motif, which is also found in the mammalian telomere. Owing to its wide range of inhibition targets, A151 affects various immune cells, including macrophages, type $1 \mathrm{~T}$ helper cells, and regulatory T cells. ${ }^{7-9)}$ Moreover, previous studies have demonstrated that A151 was useful to protect against lethal endotoxic shock, ${ }^{7}$ and to treat autoimmune hepatitis, ${ }^{10)}$ and inflammatory lung cancer. ${ }^{11)}$ In those previous studies, A151 was administered by simple injection for the treatment of diseases, and few attempts have been made to enhance its immunosuppressive activity so far.

An efficient approach to enhance the biological activity of functional nucleic acids is to improve their delivery to target cells. This can be achieved by constructing nanostructured DNA. ${ }^{12)}$ Nanostructured DNA can be obtained by hybridisation between cDNA strands. ${ }^{13)}$ Various nanostructured DNAs have been reported, including DNA origami, ${ }^{14)}$ DNA tiles, ${ }^{15}$ ) and DNA tetrahedra. ${ }^{16)}$ We previously designed polypod-like nanostructured DNA (polypodna), which consists of three or more phosphodiester single-stranded DNAs. ${ }^{17)}$ Our previous studies demonstrated that the formation of polypodna significantly enhanced the immunostimulatory activity of a $\mathrm{CpG}$ ODN after its addition to mouse immune cells, such as macrophages and bone marrow-derived dendritic cells. ${ }^{18)}$ A higher immunostimulatory activity was obtained when more DNA strands were used for the preparation of polypodna. ${ }^{17}$

Polypodna could also be useful for the delivery of immunosuppressive ODN, although few attempts have been made to address the issue. In this study, therefore, we evaluated the efficacy of polypodna as a delivery carrier for immunosuppressive A151 to enhance its immunosuppressive activity. We selected hexapodna, a polypodna consisting of six singlestranded ODNs, as a carrier for A151. Then, we incorporated A151 into the hexapodna to obtain a suppressive hexapodna, or supHexapodna. We evaluated the formation of supHexapodna and assessed its biological activities in comparison with free A151. 


\section{MATERIALS AND METHODS}

Chemicals Roswell Park Memorial Institute medium was obtained from Nissui Pharmaceutical Co., Ltd. (Tokyo, Japan). Opti-modified Eagle's medium (Opti-MEM) and fetal bovine serum were purchased from Thermo Fisher Scientific Inc. (Waltham, MA, U.S.A.). The 20 and 100-bp DNA ladders were purchased from TaKaRa Bio, Inc. (Shiga, Japan). All other chemicals were of the highest grade available and used without further purification.

Oligodeoxynucleotides All unlabelled phosphodiester and phosphorothioate ODNs were purchased from Integrated DNA Technologies (Coralville, IA, U.S.A.). These ODNs were dissolved in Tris-ethylenediaminetetraacetic acid (TE) buffer (10 mm Tris- $\mathrm{HCl}, 1 \mathrm{~mm}$ ethylenediaminetetraacetic acid, $\mathrm{pH} 8$ ) and then stored at $-20^{\circ} \mathrm{C}$. The sequences of the ODNs used in this study are shown in Table 1 . CpG 1668 was used as a ligand for TLR9. A151 and CpG 1668 labelled with Alexa Fluor 488 at the $5^{\prime}$ end were purchased from Japan BioService Co., Ltd. (Saitama, Japan).

Cell Culture Mouse macrophage-like RAW264.7 cells were cultured in Roswell Park Memorial Institute medium supplemented with $10 \%$ heat-inactivated fetal bovine serum, $0.15 \%$ sodium bicarbonate, $100 \mathrm{IU} / \mathrm{mL}$ penicillin, $100 \mu \mathrm{g} / \mathrm{mL}$ streptomycin, and $2 \mathrm{~mL}$ glutamine at $37^{\circ} \mathrm{C}$ in humidified air containing $5 \% \mathrm{CO}_{2}$. The cells were seeded in 96-well culture plates at a density of $5 \times 10^{4}$ cells/well and cultured for $24 \mathrm{~h}$ prior to use. Before applying DNA samples to the cells, the supernatant was removed and the cells were washed once with phosphate-buffered saline.

Preparation of Hexapodna and supHexapodna Hexapodna and supHexapodna were prepared as previously described. ${ }^{17)}$ In brief, hexapodna was prepared by mixing equimolar amounts of six phosphodiester ODNs, i.e., hexa1-6. supHexapodna was prepared by mixing the six ODNs together with a six-fold molar excess of A151. The ODNs were annealed in TE buffer containing $150 \mathrm{~mm}$ sodium chloride in a thermal cycler. Fluorescently labelled supHexapodna was also prepared using Alexa Fluor 488-labelled A151.

Polyacrylamide Gel Electrophoresis of Hexapodna and

Table 1. Sequences of Oligonucleotides Used in This Study

\begin{tabular}{|c|c|}
\hline Name & Sequence $\left(5^{\prime} \rightarrow 3^{\prime}\right)$ \\
\hline A151 & $\begin{array}{l}\mathrm{T}^{*} \mathrm{~T} * \mathrm{~A} * \mathrm{G} * \mathrm{G} * \mathrm{G} * \mathrm{~T} * \mathrm{~T} * \mathrm{~A} * \mathrm{G} * \mathrm{G} * \mathrm{G} * \mathrm{~T} * \mathrm{~T} * \mathrm{~A} * \mathrm{G} * \mathrm{G} * \mathrm{G} * \\
\mathrm{~T} * \mathrm{~T} * \mathrm{~A} * \mathrm{G} * \mathrm{G} \mathrm{G}^{a)}\end{array}$ \\
\hline hexa1 & $\begin{array}{l}\text { TAGCAGCACATCAGGT TCTGAGCCTTGCTGCA } \\
\text { CCCTAA CCCTAA CCCTAA CCCTAA }^{b)}\end{array}$ \\
\hline hexa2 & $\begin{array}{l}\text { TGCAGCAAGGCTCAGA TCTGCTCAAGCCTGCA } \\
\text { CCCTAA CCCTAA CCCTAA CCCTAA }\end{array}$ \\
\hline hexa3 & $\begin{array}{l}\text { TGCAGGCTTGAGCAGA CAGAGCCTTGAGCCTA } \\
\text { CCCTAA CCСTAA CCCTAA CCCTAA }\end{array}$ \\
\hline hexa4 & $\begin{array}{l}\text { TAGGCTCAAGGCTCTG GAGGCTCTTAAGCTGC } \\
\text { CCCTAA CCCTAA CCCTAA CCCTAA }\end{array}$ \\
\hline hexa5 & $\begin{array}{l}\text { GCAGCTTAAGAGCCTC AGAGCTTGGCATAGCA } \\
\text { CCCTAA CCCTAA CCCTAA CCCTAA }\end{array}$ \\
\hline hexa6 & $\begin{array}{l}\text { TGCTATGCCAAGCTCT ACCTGATGTGCTGCTA } \\
\text { CCCTAA CCCTAA CCCTAA CСCTAA }\end{array}$ \\
\hline CpG 1668 & TCCAT GACGT TCCTG ATGCT \\
\hline
\end{tabular}

a) Phosphorothioate linkages are shown as $*, b$ ) The complementary sequences to A151 are underlined.
supHexapodna The formation of hexapodna and supHexapodna was analysed by $6 \%$ polyacrylamide gel electrophoresis (PAGE) at $150 \mathrm{~V}$ for $30 \mathrm{~min}$. DNA was stained with SYBR Gold (Thermo Fisher Scientific, Inc.) and the polyacrylamide gel was observed under an LAS-3000 imager (FUJIFILM, Tokyo, Japan).

Circular Dichroism Spectroscopy Circular dichroism (CD) spectroscopy was conducted to analyse the conformations of A151, hexapodna, and supHexapodna. CD spectra of the DNA samples were obtained and recorded using a JASCO-820 type spectropolarimeter (JASCO, Tokyo, Japan) at $20^{\circ} \mathrm{C}$ with a $0.1-\mathrm{cm}$ path-length quartz cell. The DNA samples were diluted with TE buffer containing $150 \mathrm{~mm}$ sodium chloride to a final DNA concentration of $68 \mu \mathrm{g} / \mathrm{mL}$. The CD spectra were measured in the range of 200-320 nm.

CpG-ODN-Induced Tumour Necrosis Factor- $\alpha$ Release from RAW264.7 Cells RAW264.7 cells were incubated with $5 \mu \mathrm{M} \mathrm{CpG} 1668$ with or without other DNA samples. The concentrations used were $3 \mathrm{~nm}$ for A151, and $0.5 \mathrm{~nm}$ for hexapodna and supHexapodna, because $0.5 \mathrm{~nm}$ supHexapodna contained $0.5 \mathrm{~nm}$ hexapodna and $3 \mathrm{~nm}$ A151 (1 to $6 \mathrm{M}$ ratio). After $8 \mathrm{~h}$ incubation at $37^{\circ} \mathrm{C}$, the supernatant was removed, and the concentration of tumour necrosis factor- $\alpha$ (TNF- $\alpha$ ) in the supernatant was measured by enzyme-linked immunosorbent assay (ELISA) using an OptEIA mouse TNF (Mono/Mono) ELISA set (BD Biosciences, San Diego, CA, U.S.A.) in accordance with the manufacturer's protocol.

Uptake by RAW264.7 Cells RAW264.7 cells were incubated for $2 \mathrm{~h}$ at $37^{\circ} \mathrm{C}$ in Opti-MEM with Alexa Fluor 488-labelled A151 or Alexa Fluor 488-labelled CpG 1668 with or without unlabelled DNA. The concentrations of the DNA samples were the same as those used for the cytokine release experiment. The cells were washed thrice with phosphatebuffered saline at $4^{\circ} \mathrm{C}$ to remove labelled DNA and then harvested. Then, the fluorescence was measured by flow cytometry (Gallios flow cytometer; BD Biosciences) and the mean fluorescence intensity (MFI) of the cells was calculated using Kaluza software (BD Biosciences).

Statistical Analysis Differences were statistically evaluated by one-way ANOVA followed by the Tukey-Kramer test for multiple comparisons. $p$ values less than 0.05 were considered statistically significant.

\section{RESULTS}

Structural Analysis of Hexapodna and supHexapodna Figure 1 shows the schematic design of supHexapodna. The formation of supHexapodna was confirmed by PAGE analysis (Fig. 2). In the lane loaded with supHexapodna, the band for free, single-stranded A151 was not observed and a band with a higher molecular weight than that of hexapodna was detected. To determine the DNA conformation in supHexapodna, CD spectroscopy was conducted. It has been reported that A151 has an anti-parallel G-quadruplex conformation and shows a characteristic spectrum comprising positive bands at 210 and $290 \mathrm{~nm}$ and a negative band at $260 \mathrm{~nm} .{ }^{19)}$ By contrast, ordinary single-stranded and double-stranded B-type DNAs show a spectrum with a negative band at $245 \mathrm{~nm}$ and a broad positive band at $260-280 \mathrm{~nm}$. A previous study showed that tripodna had a similar spectrum to B-type DNA. ${ }^{17)}$ Figure 3 shows the CD spectra of A151, hexapodna, and supHexapodna. A151 
showed the characteristic spectrum of an anti-parallel G-quadruplex, while hexapodna and supHexapodna showed similar spectra to B-type DNA.

Inhibition of CpG-ODN Induced TNF- $\alpha$ Release from RAW264.7 Cells by A151 and supHexapodna The immunosuppressive activity of supHexapodna was evaluated by measuring the amount of TNF- $\alpha$ released from RAW264.7 cells after the addition of immunostimulatory $\mathrm{CpG}$ 1668. The amount of TNF- $\alpha$ released from RAW264.7 cells was more significantly reduced by the co-addition of supHexapodna than A151 or hexapodna (Fig. 4).

Cellular Uptake of A151 and CpG-ODN by RAW264.7 Cells The enhanced inhibitory activity of supHexapodna could be due to an increase in the cellular uptake of A151 or an inhibition of the uptake of CpG 1668 by RAW264.7 cells. First, the cellular uptake of Alexa Fluor 488-labelled A151 at $2 \mathrm{~h}$ after addition to RAW264.7 cells was examined under the
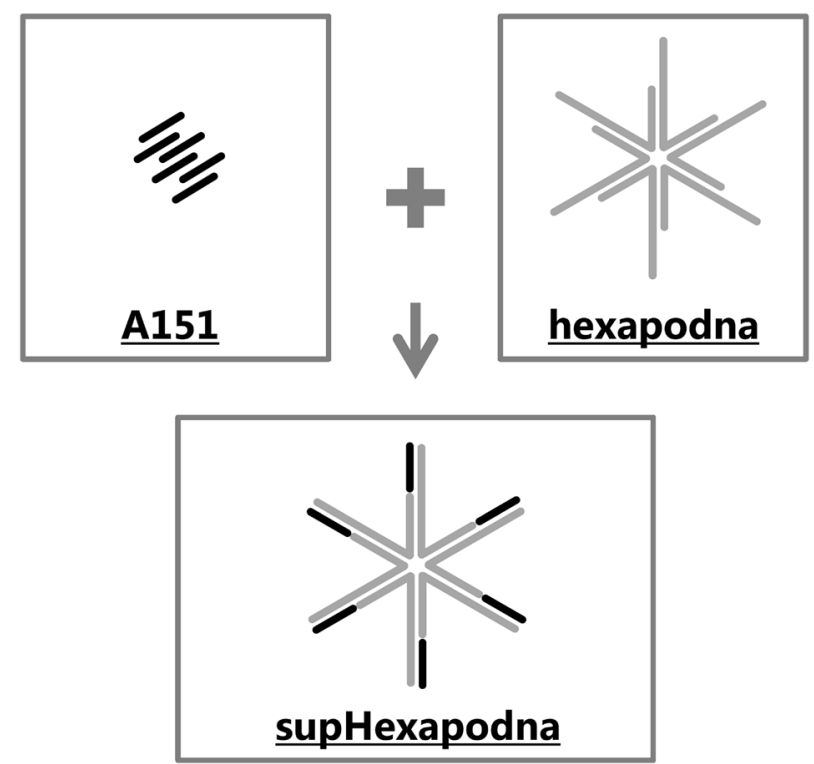

Fig. 1. Schematic Presentation of the Formation of supHexapodna same conditions as used for the cytokine release experiments and the MFI of the cells was calculated. As shown in Fig. 5a, supHexapodna, which was formed by incorporating A151 into hexapodna, showed a higher MFI than A151. Moreover, the co-incubation of $\mathrm{CpG} 1668$ with A151 and supHexapodna

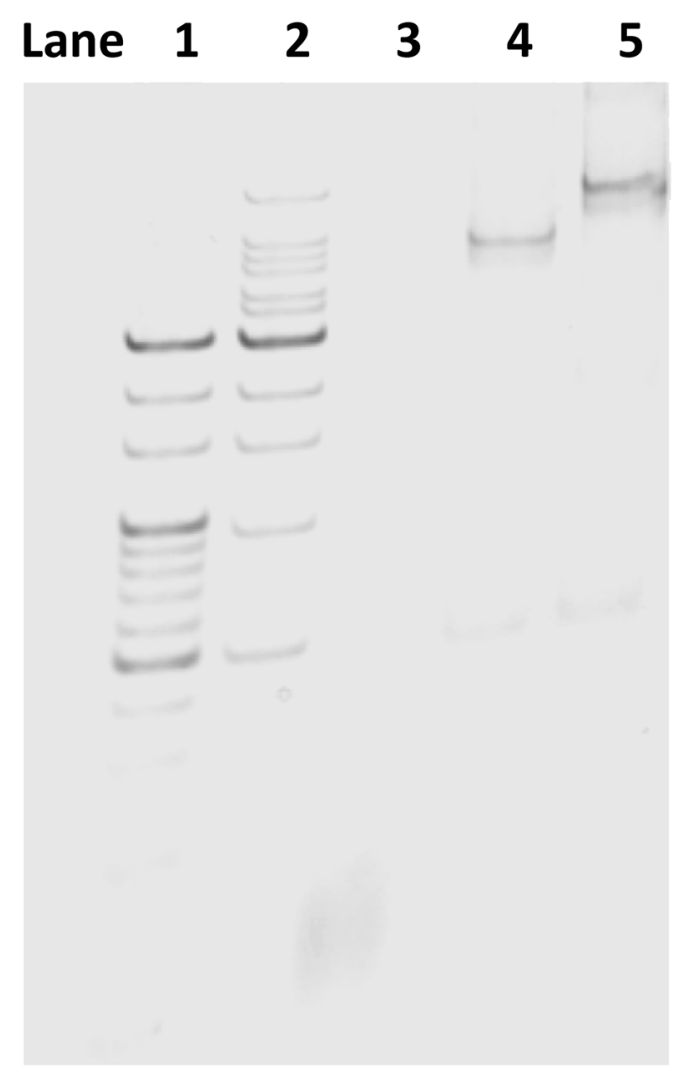

Fig. 2. PAGE Analysis of A151, Hexapodna, and supHexapodna

Hexapodna was prepared by annealing six phosphodiester oligodeoxynucleotides. supHexapodna was prepared by annealing hexapodna with a six-fold molar excess of A151. DNA samples were subjected to $6 \%$ PAGE and then the gel was stained with SYBR Gold. The image was obtained using an LAS-3000 imager. Lane 1, 20-bp DNA ladder; lane 2, 100-bp DNA ladder; lane 3, A151; lane 4, hexapodna; lane 5, supHexapodna.

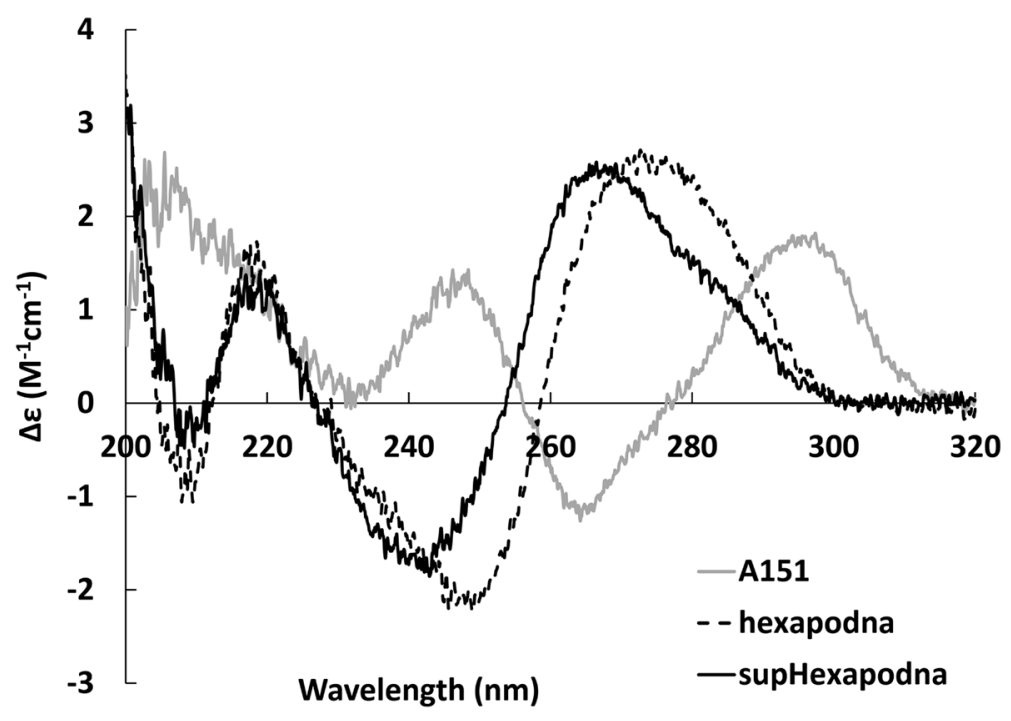

Fig. 3. CD Spectra of A151, Hexapodna, and supHexapodna

CD spectra of A151, hexapodna, and supHexapodna were measured between $200-320 \mathrm{~nm}$ using a spectropolarimeter with a $0.1-\mathrm{cm}$ path-length quartz cell in $150 \mathrm{~mm}$ sodium chloride containing TE buffer at $20^{\circ} \mathrm{C}$. 
enhanced the MFI of the cells as compared with that of cells incubated with A151 and supHexapodna but without $\mathrm{CpG}$ 1668. Then, the uptake of Alexa Fluor 488-labelled CpG 1668 was examined. No significant differences in the MFI values were observed after the co-addition of other ODNs or nanostructured DNAs (Fig. 5b).

\section{DISCUSSION}

DNA nanostructures can be used for the delivery of immu-

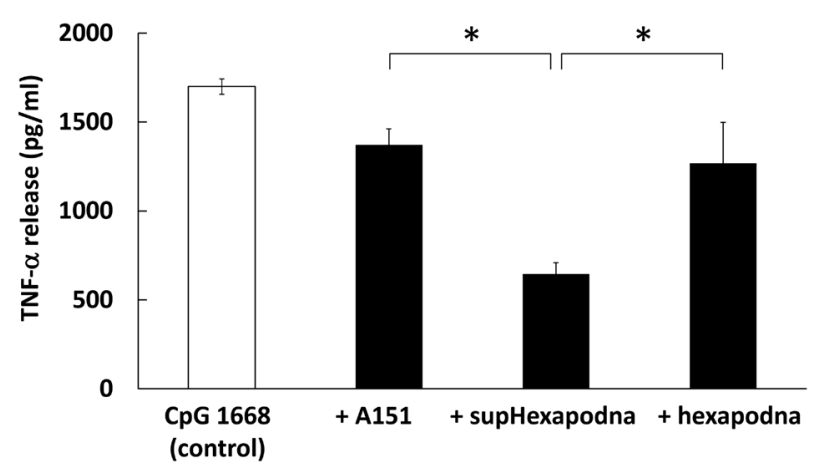

Fig. 4. Suppression of $\mathrm{CpG}$ 1668-Induced TNF- $\alpha$ Release from RAW264.7 Cells

RAW264.7 cells were incubated with CpG 1668 (control) with or without A151, supHexapodna, and hexapodna for $8 \mathrm{~h}$ at $37^{\circ} \mathrm{C}$. The concentrations were $3 \mathrm{~nm}$ for A151 and $0.5 \mathrm{~nm}$ for supHexapodna and hexapodna, because $0.5 \mathrm{~nm}$ supHexapodna contained $0.5 \mathrm{~nm}$ hexapodna and $3 \mathrm{~nm}$ A151. The concentrations of TNF- $\alpha$ in the cell culture supernatants were determined by enzyme-linked immunosorbent assay. The results are expressed as the mean \pm standard deviation (S.D.) of four culture wells. Experiments were repeated three times and representative results are shown. $*, p<0.05$. nostimulatory $\mathrm{CpG}$ ODNs to immune cells because they are efficiently taken up by these cells. In this study, to enhance the immunosuppressive activity of A151, we examined its delivery to macrophages, which are one of the possible target cell types of A151. Hexapodna was selected as a delivery carrier for A151 because it was the most efficient polypodna for improving its delivery to immune cells. ${ }^{17)}$ Recently, we found that hexapodna was efficiently taken up by immune cells, such as dendritic cells and macrophages, as compared with other types of cells including fibroblasts and endothelial cells. ${ }^{20)}$ The mechanism of this efficient uptake is under investigation, but so-called "DNA receptors"21-23) would be involved in the efficient uptake of hexapodna and other DNA nanostructures by immune cells.

According to the CD spectra (Fig. 3), A151 formed a Gquadruplex as previously reported, ${ }^{19)}$ whereas annealing with hexapodna resulted in a conformational change of A151 to a normal duplex structure. Because supHexapodna was efficiently formed by annealing (Fig. 2), these results suggest that A151 can be incorporated into hexapodna or other DNA nanostructures that contain the complementary sequence to A151.

It was previously reported that A151 hardly inhibited the cellular uptake of $\mathrm{CpG}$ ODN, but rather competed with its binding to TLR9 to inhibit $\mathrm{CpG}$ ODN-induced cytokine release. $^{6)}$ A151, hexapodna, or supHexapodna hardly affected the uptake of Alexa Fluor 488-labelled CpG 1668 by RAW264.7 cells (Fig. 5b). In addition, the uptake of $2.5 \mu \mathrm{M}$ Alexa Fluor 488-labelled (AF) CpG 1668 by RAW264.7 cells was hardly reduced by $5 \mu \mathrm{M} A 151,0.83 \mu \mathrm{M}$ hexapodna, or $0.83 \mu \mathrm{M}$ supHexapodna (data not shown). The MFI of cells incubated with CpG 1668 and AF-supHexapodna was higher
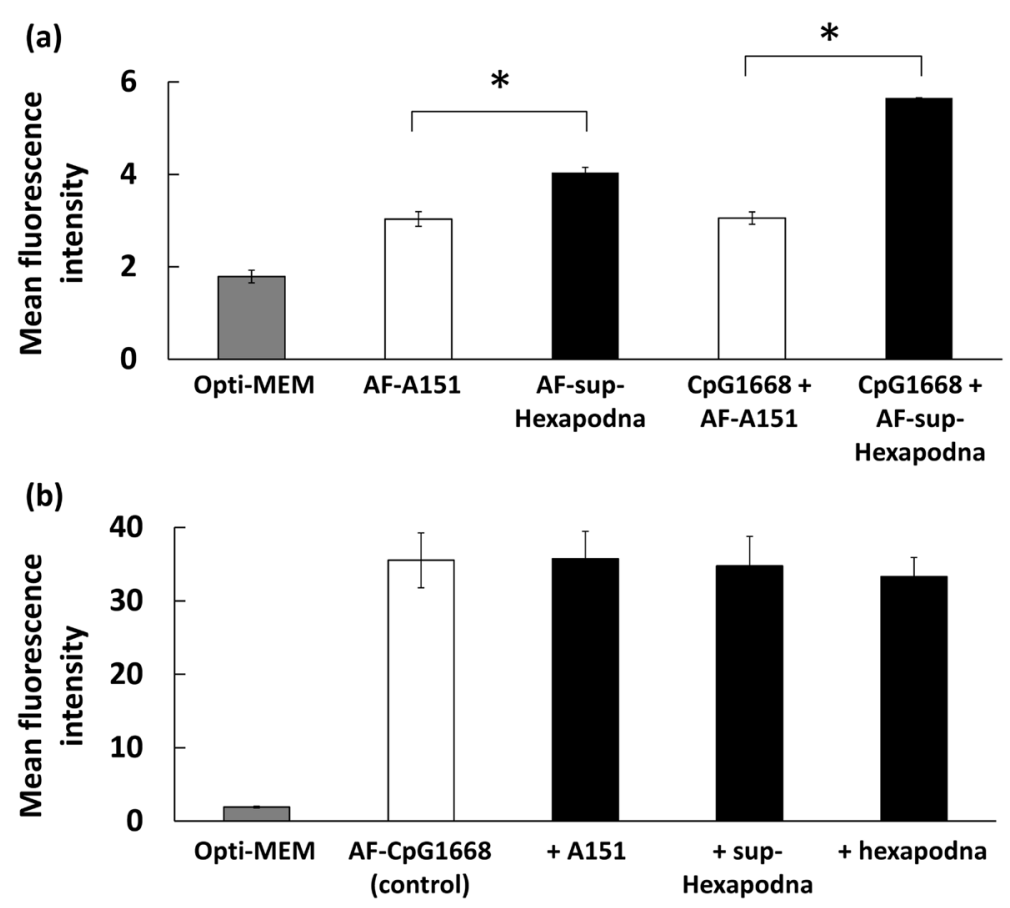

Fig. 5. Uptake of Alexa Fluor 488-Labelled DNA by RAW264.7 Cells

(a) RAW264.7 cells were incubated with Alexa Fluor 488-labelled A151 (AF-A151) or supHexapodna (AF-supHexapodna) with or without $5 \mu \mathrm{M}$ CpG 1668 for $2 \mathrm{~h}$ at $37^{\circ} \mathrm{C}$. The concentrations used were $3 \mathrm{~nm}$ for A151 and $0.5 \mathrm{~nm}$ for supHexapodna because $0.5 \mathrm{~nm}$ supHexapodna contained $0.5 \mathrm{~nm}$ hexapodna and $3 \mathrm{~nm}$ Alexa Fluor 488 -labelled A151. The mean fluorescence intensity of the cells was determined by flow cytometry. The results are shown as the mean \pm S.D. of three culture wells. Experiments were repeated three times and representative results are shown. *, $p<0.05$. (b) RAW264.7 cells were incubated with 5 $\mu$ M Alexa Fluor 488-labelled CpG 1668 (AF-CpG 1668) with or without A151, supHexapodna, or hexapodna for $2 \mathrm{~h}$ at $37^{\circ} \mathrm{C}$. The concentrations used were $3 \mathrm{~nm}$ for A151, and $0.5 \mathrm{~nm}$ for supHexapodna and hexapodna, because $0.5 \mathrm{~nm}$ supHexapodna contained $0.5 \mathrm{~nm}$ hexapodna and $3 \mathrm{~nm}$ Alexa Fluor 488 -labelled A151. The mean fluorescence intensity of the cells was calculated by flow cytometry. The results are shown as the mean \pm S.D. of four culture wells. Experiments were repeated three times and representative results are shown. 
than that incubated with AF-supHexapodna (Fig. 5a). This may be because CpG 1668 activated the cells, which then led to the enhanced uptake of nanostructured DNA like supHexapodna. Therefore, the increased uptake of A151 as a part of the supHexapodna complex seems to underpin the higher immunosuppressive activity of supHexapodna than free A151 and hexapodna (Fig. 4). The activity of supHexapodna containing $3 \mathrm{~nm}$ A151 was comparable to that of $30 \mathrm{~nm}$ A151 (data not shown), suggesting that hexapodna can reduce the dose of A151. Hexapodna containing no inhibitory ODNs somewhat reduced TNF- $\alpha$ release from the cells after addition of $\mathrm{CpG}$ 1668. We sometimes observed that $\mathrm{CpG}$ 1668-induced TNF- $\alpha$ release from RAW264.7 cells was reduced by co-incubation with other DNA samples irrespective of the presence of inhibitory sequences, suggesting some non-sequence-specific effects of added DNAs.

It was previously reported that the G-quadruplex structure of A151 was required for its immunoinhibitory activity. ${ }^{6}$ When A151 was incorporated into hexapodna, the G-quadruplex conformation of A151 was lost, so we supposed that A151 is unlikely to inhibit $\mathrm{CpG} 1668$-induced cytokine release while it is a constituent of supHexapodna. In the present study, we did not evaluate the release of A151 from supHexapodna. However, previous results on DNA nanostructures containing CpG ODNs suggested that the ODNs comprising the nanostructures dissociated in the endosomal compartments after their cellular uptake. ${ }^{17)}$ The melting temperature between A151 and hexapodna was lower than that of DNAs used in previous studies, because A151 has a phosphorothioate backbone. Therefore, it could be speculated that A151 can be released from supHexapodna in the endosomes after its cellular uptake. After being released from supHexapodna, A151 is likely to form a G-quadruplex in the endosome. TLR9 localises in the endosomes, and the released A151 could inhibit the binding of CpG 1668 to TLR9 in that cellular compartment.

The results of the present study indicated that supHexapodna had a higher immunosuppressive activity than A151. Therefore, hexapodna can be effective in reducing the dose of A151 that needs to be administered to have an immunosuppressive activity. It was reported that mipomersen ${ }^{24)}$ and drisapersen, ${ }^{25}$ both of which are phosphorothioate nucleic acids, induced hepatic and renal toxicity at high doses in clinical trials. Thus, lowering the dose of A151 would be beneficial for reducing its toxicity.

\section{CONCLUSION}

In this study, we designed supHexapodna by incorporating A151 into hexapodna to yield an enhanced immunosuppressive activity of A151. The results demonstrated that supHexapodna is an effective DNA nanostructure for mediating the efficient delivery of A151 to immune cells to inhibit $\mathrm{CpG}$ ODN-induced cytokine release.

Acknowledgments This work was supported in part by the Japan Society for the Promotion of Science under Grantsin-Aid for Scientific Research (B) 23390010 and 26293008, and by JST CREST, Japan under Grant JPMJCR1521.

Conflict of Interest The authors declare no conflict of interest.

\section{REFERENCES}

1) Gay NJ, Symmons MF, Gangloff M, Bryant CE. Assembly and localization of Toll-like receptor signalling complexes. Nat. Rev. Immunol., 14, 546-558 (2014).

2) Bayik D, Gursel I, Klinman DM. Structure, mechanism and therapeutic utility of immunosuppressive oligonucleotides. Pharmacol. Res., 105, 216-225 (2016).

3) Klinman DM, Zeuner R, Yamada H, Gursel M, Currie D, Gursel I. Regulation of CpG-induced immune activation by suppressive oligodeoxynucleotides. Ann. N. Y. Acad. Sci., 1002, 112-123 (2003).

4) Yamada H, Gursel I, Takeshita F, Conover J, Ishii KJ, Gursel M, Takeshita S, Klinman DM. Effect of suppressive DNA on CpGinduced immune activation. J. Immunol., 169, 5590-5594 (2002).

5) Lenert PS. Classification, mechanisms of action, and therapeutic applications of inhibitory oligonucleotides for Toll-like receptors (TLR) 7 and 9. Mediators Inflamm., 2010, 986596 (2010).

6) Gursel I, Gursel M, Yamada H, Ishii KJ, Takeshita F, Klinman DM. Repetitive elements in mammalian telomeres suppress bacterial DNA-induced immune activation. J. Immunol., 171, 1393-1400 (2003).

7) Shirota H, Gursel I, Gursel M, Klinman DM. Suppressive oligodeoxynucleotides protect mice from lethal endotoxic shock. J. Immunol., 174, 4579-4583 (2005).

8) Shirota H, Gursel M, Klinman DM. Suppressive oligodeoxynucleotides inhibit Th1 differentiation by blocking IFN-gamma- and IL12-mediated signaling. J. Immunol., 173, 5002-5007 (2004).

9) Bode C, Wang J, Klinman DM. Suppressive oligodeoxynucleotides promote the generation of regulatory $\mathrm{T}$ cells by inhibiting STAT1 phosphorylation. Int. Immunopharmacol., 23, 516-522 (2014).

10) Li N, Liu YH, Li SL, Fu CY, Zhou RR, Huang Y, Fan XG. Protective role of synthetic oligodeoxynucleotides expressing immunosuppressive TTAGGG motifs in concanavalin A-induced hepatitis. Immunol. Lett., 151, 54-60 (2013).

11) Bode C, Kinjo T, Alvord WG, Klinman DM. Suppressive oligodeoxynucleotides reduce lung cancer susceptibility in mice with silicosis. Carcinogenesis, 35, 1078-1083 (2014).

12) Li J, Fan C, Pei H, Shi J, Huang Q. Smart drug delivery nanocarriers with self-assembled DNA nanostructures. Adv. Mater., 25, 4386-4396 (2013).

13) Jones MR, Seeman NC, Mirkin CA. Programmable materials and the nature of the DNA bond. Science, 347, 1260901 (2015).

14) Rothemund PWK. Folding DNA to create nanoscale shapes and patterns. Nature, 440, 297-302 (2006).

15) Wei B, Dai M, Yin P. Complex shapes self-assembled from singlestranded DNA tiles. Nature, 485, 623-626 (2012).

16) Goodman RP, Berry RM, Turberfield AJ. The single-step synthesis of a DNA tetrahedron. Chem. Commun., 12, 1372-1373 (2004).

17) Mohri K, Nishikawa M, Takahashi N, Shiomi T, Matsuoka N, Ogawa K, Endo M, Hidaka K, Sugiyama H, Takahashi Y, Takakura Y. Design and development of nanosized DNA assemblies in polypod-like structures as efficient vehicles for immunostimulatory $\mathrm{CpG}$ motifs to immune cells. ACS Nano, 6, 5931-5940 (2012).

18) Uno S, Nishikawa M, Mohri K, Umeki Y, Matsuzaki N, Takahashi Y, Fujita H, Kadowaki N, Takakura Y. Efficient delivery of immunostimulatory DNA to mouse and human immune cells through the construction of polypod-like structured DNA. Nanomedicine, 10, 765-774 (2014).

19) Kypr J, Kejnovská I, Renciuk D, Vorlícková M. Circular dichroism and conformational polymorphism of DNA. Nucleic Acids Res., 37, 1713-1725 (2009)

20) Mohri K, Nagata K, Ohtsuki S, Toyama S, Nonomura M, Takahashi Y, Takakura Y, Nishikawa M, Sakuma S. Elucidation of the mechanism of increased activity of immunostimulatory DNA by the formation of polypod-like structure. Pharm. Res., 34, 2362-2370 (2017). 
21) Kimura $Y$, Sonehara $K$, Kuramoto E, Makino T, Yamamoto S, Yamamoto T, Kataoka T, Tokunaga T. Binding of oligoguanylate to scavenger receptors is required for oligonucleotides to augment NK cell activity and induce IFN. J. Biochem., 116, 991-994 (1994).

22) Sirois CM, Jin $T$, Miller AL, Bertheloot $D$, Nakamura $H$, Horvath GL, Mian A, Jiang J, Schrum J, Bossaller L, Pelka K, Garbi N, Brewah Y, Tian J, Chang C, Chowdhury PS, Sims GP, Kolbeck R, Coyle AJ, Humbles AA, Xiao TS, Latz E. RAGE is a nucleic acid receptor that promotes inflammatory responses to DNA. J. Exp. Med., 210, 2447-2463 (2013).

23) Benimetskaya L, Loike JD, Khaled Z, Loike G, Silverstein SC, Cao L, el Khoury J, Cai TQ, Stein CA. Mac-1 (CD11b/CD18) is an oligodeoxynucleotide-binding protein. Nat. Med., 3, 414-420 (1997).

24) Santos RD, Duell PB, East C, Guyton JR, Moriarty PM, Chin W, Mittleman RS. Long-term efficacy and safety of mipomersen in patients with familial hypercholesterolaemia: 2-year interim results of an open-label extension. Eur. Heart J., 36, 566-575 (2015).

25) Flanigan KM, Voit T, Rosales XQ, Servais L, Kraus JE, Wardell C, Morgan A, Dorricott S, Nakielny J, Quarcoo N, Liefaard L, Drury T, Campion G, Wright P. Pharmacokinetics and safety of single doses of drisapersen in non-ambulant subjects with Duchenne muscular dystrophy: results of a double-blind randomized clinical trial. Neuromuscul. Disord., 24, 16-24 (2014). 